\title{
LA IRONÍA Y LA CORTESÍA: UNA APROXIMACIÓN DESDE SUS EFECTOS
}

\author{
M. Belén Alvarado Ortega \\ Universidad de Alicante \\ Grupo GRIALE \\ Belen.Alvarado@ua.es
}

\begin{abstract}
Resumen
Este artículo presenta un análisis de la ironía verbal en relación con la cortesía. El objetivo fundamental es demostrar que la cortesía puede estar presente en un enunciado irónico y se puede utilizar como estrategia para producir ironía. Proponemos una clasificación según los efectos de la ironía, basada en el análisis de ejemplos reales.
\end{abstract}

PALABRAS CLAVE: Ironía verbal, cortesía, imagen, burla.

\begin{abstract}
This article presents an analysis of one of the most controversid pragmatic phenomenon, verbal irony. It focuses on the study of irony on relation to politeness. My purpose is to demonstrate that politeness could be used as a strategy to produce irony. Specifically, I propose a classification based on the analysis of real examples in order to conclude that politeness can be connected with positive effects.

KEY WORDS: Verbal irony, politenees, face, gibe.
\end{abstract}

\section{Introducción}

En el trabajo que presentamos proponemos un esquema según los efectos que tiene la ironía cuando se produce en un enunciado. Hasta el momento se ha creído que la ironía siempre tenía un efecto negativo, es decir, se ha asociado siempre con la crítica y la burla; sin embargo, en este artículo explicaremos que no sólo tiene efecto negativo, sino también positivo y puede llevar consigo cortesía. De esta manera, relacionamos la cortesía con una ironía de efecto positivo en la que no habrá lugar para la burla. Intentamos demostrar que la cortesía puede estar presente en un enunciado y se puede utilizar como una estrategia para producir ironía.

Para conseguir nuestro objetivo nos basamos en las investigaciones que está llevando a cabo el grupo GRIALE, dirigido por Leonor Ruiz Gurillo, sobre la ironía verbal en español y en los estudios de cortesía más importantes, entre los que se encuentran Brown y Levinson $(1978,1987)$, Bravo y Briz (eds.) (2004) y las aportaciones del proyecto EDICE. Algunos de nuestros ejemplos se han extraído de corpora orales del español entre los que se encuentra el ALCORE (Alicante Corpus Oral del Español) y el Corpus de conversaciones coloquiales de Briz y el grupo Val.Es.Co. (2002).

1 Este artículo ha sido posible gracias al Proyecto HUM2004-01318/FILO, concedido por el Ministerio de Educación y Ciencia, que se titula "Análisis pragmático de la ironía verbal. Tipología y aplicaciones a la enseñanza del español como lengua extranjera". 
A continuación, daremos unas breves pautas del funcionamiento de estos dos fenómenos pragmáticos.

\section{La ironía}

Hasta hace poco, la ironía se ha definido a partir de los parámetros de la retórica tradicional en los que se afirmaba que la ironía era decir lo contrario de lo que se quiere decir. Esta definición ha sido criticada por autores como Haverkate (1985), que considera que el concepto de contradicción no es suficiente para unificar todos los fenómenos irónicos. Además, la existencia de una contradicción no caracteriza a los enunciados como irónicos, ya que puede haber enunciados irónicos con sentido figurado que no llevan una contradicción implícita. En muchas ocasiones, lo que indica la ironía no es un significado opuesto, sino diferente. Por ello, estudiamos la ironía como fenómeno pragmático y proponemos una teoría para el análisis que parte de las teorías neogriceanas, puesto que el hablante tiene una intención clara de comunicar algo cuando utiliza un enunciado irónico. De esta manera, pretende que su oyente infiera lo que no ha dicho para obtener el significado completo de su enunciación.

La Teoría de la Relevancia se ha pronunciado al respecto y ha propuesto una explicación para la ironía basada en el concepto de eco. Según Wilson y Sperber (2004: 265) "un enunciado es irónico porque es ecoico: la ironía verbal consiste en hacerse eco de un pensamiento o emisión que se atribuye de modo tácito, mediante una actitud distante y también tácita respecto a ella." Por tanto, la ironía se estudia como un distanciamiento hacia un pensamiento o un enunciado atribuidos a alguien y siempre llevará consigo un contexto que pueda ser entendido como un eco burlón. Según esta teoría toda ironía produce un eco con efecto negativo, es por ello que intentamos demostrar que no todo enunciado irónico lleva consigo ese eco burlón, sino que existe ironía con efecto positivo en la que la burla no está presente.

En nuestro trabajo, como veremos posteriormente, partimos de las teorías neogriceanas, sin abandonar totalmente la noción de eco que plantea la Teoría de la Relevancia. Por ello debemos explicar dos enfoques pragmáticos que han intentado resolver los problemas que plantean los enunciados irónicos: las teorías griceanas y las teorías polifónicas. La primera de ellas relaciona la ironía con el Principio de Cooperación de Grice (1975). Cada vez que aparece la ironía es porque se ha violado una máxima y no se cumple dicho principio. Veamos un ejemplo en el que Mario pronostica el tiempo para el día siguiente y afirma que va a hacer un tiempo estupendo para ir a la playa. Al día siguiente amanece lloviendo. Su amiga le comenta:

\section{(1) M: Eres Rappel.}

En este ejemplo, es totalmente falso que Mario sea Rappel (vidente reconocido en el ámbito español), ni siquiera que tenga sus dotes adivinatorias. Por tanto, Mario debe entender otra cosa, en este caso, que no ha adivinado el tiempo que ha hecho, es más, que ni siquiera se ha aproximado. $\mathrm{M}$ ha violado la máxima de cualidad $\mathrm{y}$, por tanto, se infieren las implicaturas que dan lugar a la ironía, puesto que los hechos no son veraces y no enuncia lo que realmente quiere decir. 
Por otro lado, las teorías polifónicas, cuyo máximo representante ha sido Ducrot (1986), consideran que hay dos significados en todo enunciado irónico y se ven como un fenómeno ecoico, puesto que se alude a un significado que no se encuentra en el enunciado y que se recupera como eco de algo dicho anteriormente. Veamos un ejemplo en el que Marta y Luis están planeando su luna de miel; Luis quiere ir a Canarias, pero a Marta le da miedo subir en avión. Marta escucha en las noticias que un avión ha tenido que realizar un aterrizaje forzoso, y afirma:

(2) M: Ahora si que voy a subir en avión.

En este ejemplo, entendemos que hay dos puntos de vista inconciliables: el pensamiento de Marta y el de Luis. En este enunciado, el locutor (Marta) retoma el punto de vista de Luis y lo ridiculiza con el uso de la ironía. Desde esta postura el locutor retoma una proposición, que aparece como eco de algo que se ha dicho y que subyace al enunciado (una primera voz), para rechazarla de forma irónica (una segunda voz). De esta manera, en todo enunciado irónico hay dos voces que hacen oír tanto el sí como el no con sus palabras. Una de ellas está presente y la otra se recupera como eco de lo dicho anteriormente.

Estos enfoques anteriores nos muestran que para entender la ironía, debemos tener en cuenta el contexto lingüístico o cotexto, el contexto situacional o circunstancias externas, y el contexto sociocultural o conocimiento, vivencias compartidas, etc ${ }^{2}$. El hablante se distancia de sus palabras y el oyente ${ }^{3}$ debe inferir el significado del enunciado recurriendo a esos tres tipos de contextos. Además, el hablante debe dejar en su enunciación una serie de indicadores para que el oyente pueda interpretar que su enunciado es irónico, y que hemos presentado en un trabajo anterior (Alvarado, en prensa).

Como hemos dicho en líneas anteriores, la postura que adoptamos en nuestro trabajo parte de las teorías neogriceanas, que es donde actualmente se encuentra trabajando el grupo GRIALE, ya que consideramos que la ironía tiene un significado inferido y conversacional, pues lo comunicado en un enunciado irónico se consigue gracias a la inversión de las máximas conversacionales que retoma y modifica Levinson (2000) de Grice (1975). Este autor reduce las cuatro máximas de Grice (cantidad, cualidad, pertinencia y manera) a tres principios (informatividad, manera y cantidad) y supone la máxima de cualidad como requisito previo a la comunicación que asume tanto hablante como oyente.

Rodríguez Rosique (2005) afirma que "en los enunciados irónicos, esa pre-condición de cualidad se ve transgredida, lo que conlleva una inversión de los principios conversacionales, que entendemos como el Principio de Inversión"4. El hablante viola el requisito de sinceridad e impone al oyente a través del contexto la siguiente instrucción: Interprete el enunciado a partir de la inversión de los principios conversacionales. El contexto es el encargado de advertir al oyente que el hablante ha violado la máxima de cualidad y que, por ello, los principios conversacionales funcionan a la inversa. Esta teoría pragmática, que parte del Principio de Inversión, nos permite explicar un mayor número de ejemplos irónicos con

2 Tal y como expuso GRIALE en las VII Jornadas de Estudios de Lingüística, Alicante, 2005.

3 Utilizaremos el término oyente tal y como afirma Padilla (2005: 213), ya que tanto hablante como oyente son términos que pertenecen a la pragmática como disciplina encargada del análisis de lengua en uso.

4 Tal y como expuso en $38^{\circ}$ Congreso de la Societas Española de Lingüística Europaea, Universidad de Valencia, 2005. 
significado inferido, como veremos posteriormente. A continuación nos centraremos en la cortesía y en sus aportaciones a la ironía.

\section{La cortesía}

Han sido muchos los investigadores que se han ocupado de este fenómeno como parte fundamental del comportamiento social. Destacamos, sobre todo, las primeras aproximaciones teóricas, entre las que se encuentran las obras de Lakoff (1973), Brown y Levinson $(1978,1987)$ y Leech (1983). Lakoff y Leech, de forma individual, basan su teoría partiendo del Principio de Cooperación de Grice y se centran en el principio de cortesía que tiene una relevancia especial. Sin embargo, la teoría más influyente hasta el momento ha sido la propuesta por Brown y Levinson, puesto que introduce el concepto de imagen positiva e imagen negativa. Nos basaremos en esta última, ya que estos términos son los que vamos a intentar relacionar con la ironía.

La cortesía se puede entender de dos modos diferentes. En primer lugar, la cortesía se define como un conjunto de normas sociales, que se establecen en cada sociedad y regulan el comportamiento de sus integrantes. De esta manera, lo que se ajusta a la norma sería cortés, mientras que lo que no se ajusta a la norma sería descortés. En segundo lugar, la cortesía se puede estudiar como una estrategia conversacional capaz de evitar conflictos y mantener buenas relaciones entre los individuos de la sociedad. Para Brown y Levinson (1987: 13), la cortesía se centra bajo el concepto de imagen pública, que hay que proteger y, para ello, hay que evitar dañar la imagen pública de los demás.

Central to our model is a highly abstract notion of face which consists of two specific kinds of desire (face-wants) attributed by interactants to one another: the desire to be unimpeded in one's actions (negative face), and the desire (in some respects) to be approved of (positive face).

Este último concepto se divide en dos: imagen positiva e imagen negativa. La imagen positiva es aquella que el individuo tiene de sí mismo y que aspira a que sea reconocida por el resto de miembros, esto es, que se acepte su forma de ser en alguna de sus manifestaciones. La imagen negativa se refiere al deseo de cada individuo de que sus actos no sean irrespetados por otros, es decir, que sus acciones no sean impedidas y se afianza su derecho a la intimidad. De esta manera, el hablante desarrolla estrategias de comunicación que le sirven para mantener su imagen positiva y para defender su imagen negativa ante el oyente. Estas estrategias de cortesía estarán presentes en un tipo concreto de ironía que carece de burla, la ironía con efecto positivo, que estudiaremos a partir del punto 4.2. Por ello afirmamos que la cortesía aporta a la ironía los conceptos de imagen negativa e imagen positiva.

Ahora nos detendremos en analizar la cortesía como estrategia de comunicación y en las relaciones que puede mantener con la ironía.

\section{La ironía y la cortesía: un acercamiento desde la ironía}

Afirma Bravo (2003: 101-102) que 
la cortesía es siempre una estrategia para quedar bien con el otro ya sea manifestada como un objetivo primordial (por ejemplo un saludo, un agradecimiento, un halago) ya sea que se trate de una atenuación de algo que puede hacer quedar al hablante como rudo y descortés frente a sus interlocutores (una crítica inapropiada) o de ser particularmente amable con el objetivo de obtener beneficios extrainterlocutivos.

De ahí que la cortesía se produzca siempre en una interacción en la que el oyente participa interpretando que su hablante quiere ser cortés, de igual modo ocurre con el fenómeno de la ironía.

Por su parte, Brown y Levinson $(1978,1987: 213)$ enumeran en su obra una serie de estrategias para producir cortesía a través del lenguaje, entre las que está la ironía. Según estos autores, la ironía ayudaría al hablante a defender su imagen social ${ }^{5}$ a través de implicaturas conversacionales, es decir, que el hablante no sería claro en su intervención, puesto que viola la máxima de cualidad, y su oyente debería inferir lo que le está intentando comunicar en un enunciado irónico. Con todo ello, deducimos que la ironía es una estrategia que puede utilizar la cortesía para llegar a su último fin, pero no por ello es imprescindible. Así, demostraremos que hay enunciados irónicos que pueden ser corteses a diferencia de lo que se ha pensado hasta el momento.

Alba Juez (1995: 14) distingue entre ironía positiva e ironía negativa, según se utilice para alabar o para criticar, respectivamente. Además, relaciona estos dos tipos de ironía con las estrategias de cortesía positiva y negativa, es decir que si aparece ironía en la que se alaba a alguien habrá estrategias corteses positivas, mientras que si hay ironía y se critica, las estrategias pertenecerán a la cortesía negativa. De este modo, podemos afirmar que nuestra propuesta va más allá de la que plantea Alba Juez, ya que distinguimos dos tipos de ironía según sus efectos.

A nuestro modo de ver, en la ironía como hecho pragmático, el hablante tiene una intención clara de comunicar algo cuando utiliza un enunciado irónico. Así pretende que su oyente infiera lo que no se ha dicho, a partir del Principio de Inversión, para obtener el significado completo de su enunciación. De esta manera, cuando un enunciado es irónico puede tener un efecto negativo o positivo. Lo que distingue estos dos tipos de efectos es la presencia o ausencia de burla, es decir que si con la ironía se está produciendo burla estaremos ante ironía con efecto negativo, mientras que si hay ausencia de burla estaremos ante una ironía con efecto positivo. Tomamos la burla como parámetro delimitador, puesto que hasta el momento es la característica más común que se le ha atribuido a la ironía verbal (véase Wilson y Sperber, 2004) e intentamos demostrar que no toda ironía lleva consigo burla A continuación, proponemos nuestro esquema y una breve explicación que se desarrollará a partir del punto 4.1 .:

- IRONÍA CON EFECTO NEGATIVO

-Hacia su oyente

-Hacia una persona ausente

-Hacia una situación 
- IRONÍA CON EFECTO POSITIVO

$>$ Ironía de imagen negativa

-Auto-ironía

$>$ Ironía de imagen positiva

-Hacia su oyente

-Hacia una persona ausente

-Hacia una situación

De este modo, distinguimos dos variables de ironía según sus efectos. Se da ironía con efecto negativo en un enunciado cuando hay presencia de burla hacia su oyente, hacia una persona ausente o hacia una situación. Si en el enunciado irónico hay ausencia de burla estamos ante una ironía con efecto positivo. Este último tipo puede ser a su vez de imagen negativa o de imagen positiva ${ }^{6}$. Si es de imagen negativa, se produce auto-ironía en la que el hablante pretende conservar su imagen social y que el resto de miembros de la conversación reconozcan su forma de ser y actuar. Si es de imagen positiva, el hablante desea integrarse en el grupo conversacional y la ironía se puede producir hacia su oyente, hacia una persona ausente o hacia una situación.

\subsection{Ironía con efecto negativo}

En el caso de que el efecto que se haya producido en un enunciado irónico sea negativo, esto es, que haya burla. Esta burla puede ir dirigida hacia su oyente, hacia una persona ausente o hacia una situación. Nunca hay ironía con efecto negativo hacia uno mismo, ya que si se hiciera tendría un efecto mitigador en la conversación, es decir, tendría otra finalidad más allá de la propia burla, como veremos en el ejemplo (6).

Si la burla en la ironía de efecto negativo se produce hacia su oyente, hay también ausencia de cortesía, ya que no se puede ser cortés cuando se amenaza la imagen social del otro. También ocurre cuando la burla va dirigida hacia una persona ausente o hacia una situación. Veamos algunos ejemplos. En el siguiente contexto, A y B son un matrimonio que hablan sobre el coche que se compró una tercera persona, posiblemente el hijo de ambos:

(3) A: se lo compró p'así se fue a Palma

B: p'así que se fue/pero ehtuvo poco tiempo sin

A: no tanto tiempo fue

B: poh poco/para lo que se ehtuvo aquí y lo que se pasó /((así que se lo compró))

A: no/pos lo que se ehtuvo allí (( ))

B: tú eh que no queríah/ tú eh que decíah que no se lo comprara ((y yo estaba aquel día que no me veía))/ya sabeh que te dijee haberle-haberle sujetao que no se hubiera sacao el carnéel/porque [eh verdad]

A: [tú]/ tú sabeh mucho/ ereh mu [lihta]

B: no muy lihta/ lo que yo soy eh que no soy tonta

(Briz y Grupo Val.Es.Co. 2002: 255 [BG.210.A.1])

6 Estos términos provienen de las teorías referentes a la cortesía. 
En (3), A está atentando contra la imagen social que tiene B utilizando la ironía, ya que pretende dar a entender algo diferente de lo que realmente está afirmando, y que se puede explicar a partir del Principio de Inversión. En nuestro ejemplo, A transgrede los principios conversacionales, puesto que no dice la verdad, y B debe interpretar tú sabeh mucho/ ereh mu lista como sabes pocoleres poco lista de acuerdo con el Principio de Inversión. Este hecho da lugar a la aparición de implicaturas escalares, ya que al decir mucho/muy realmente quiere decir poco. Por tanto, la ironía se explicaría de acuerdo a ese principio. Además, tiene un efecto negativo sobre su oyente, ya que hay burla y, como consecuencia, no está presente la cortesía.

En (4), están hablando dos primas A y C ante la madre de C (B) sobre una tercera persona ausente en la conversación y el mal gusto que tiene para elegir la ropa:

(4) A: PUES SONIA// se compró a gusto de él un traje gris/// ahí (a)bajo que parece el yayo Pepe/le he dicho/ ese/ [suelto=]

$\mathrm{B}:$ [sí]

A: =que diga la-la Ana [Belén=]

C: uy pues si es muy bonito

A: SUELTO se lo pongo/ el pantalón solo/con cualquier cosa//nena/un agüelo [con lo mayor que estamos/ que estamos gordos/ pero DELANTE DE TODOS LE DIGO]

C: [í sí sí pero un ¡ABUELO! (( ))] el yayo Pepe

(Briz y Grupo Val.Es.Co. 2002: 316 [EL.116.A.1])

C interviene en la conversación con un enunciado irónico que lleva consigo burla para dar a entender que realmente el traje no es bonito. Se produce ironía de efecto negativo hacia una persona ausente en la conversación y que todos conocen. El oyente debe inferir que los principios conversacionales funcionan a la inversa, puesto que se ha violado la pre-condición de sinceridad y el hablante afirma que es muy bonito cuando en realidad quiere decir que es poco bonito. Por tanto, a partir del Principio de Inversión, podemos explicar que el significado de este enunciado irónico difiere de lo que realmente se ha dicho. Estamos ante un tipo de ironía con efecto negativo hacia una persona ausente en la conversación y con ausencia de cortesía.

En el ejemplo (5) están hablando tres compañeros de trabajo, profesores, sobre la capacidad de expansión que tienen los mensajes en internet:

(5) C: [¿por internet] mandan eso?

B: y mándela a sus amigos/ asi su suerte cambiará y-de- y fulanito de tal en Nevada que no la escribió y se murió su suegra (su suegra no porque sería una suerte)

A: sería una suerte [(RISAS)]

$\mathrm{B}:[(\mathrm{RISAS})]$ y menganito que sí la escribió le tocaron tres millones en la loteria

(Briz y Grupo Val.Es.Co. 2002: 358 [MT.97.A.1])

En (5) los hablantes ironizan y se mofan de una situación que se produce por internet en la que cree la mayoría de la gente. Se trata de enviar mensajes amenazadores con el fin de que ese mensaje se difunda lo máximo posible y las empresas ganen dinero a costa de los envíos que realiza la gente supersticiosa. En este caso, al igual que los anteriores, la ironía se puede explicar a partir del Principio de Inversión, puesto que cuando A afirma que sería una suerte, el oyente debe implicar que le quiere comunicar que seria una desgracia. Se 
invierte un término positivo explícito (suerte) por otro negativo implícito (desgracia). Así, estamos ante un enunciado irónico con efecto negativo hacia una situación, en el que no hay presencia de cortesía porque hay burla.

Por tanto, estaremos ante una ironía con efecto negativo siempre y cuando se produzca ironía y burla de forma simultánea sobre su oyente, sobre una persona ausente en la conversación o sobre una situación determinada. En todos estos casos hemos observado que hay ausencia de cortesía, es decir, que cuando estamos ante enunciados irónicos en los que su efecto es negativo y hay presencia de burla, no encontramos cortesía. Según los ejemplos estudiados, podemos afirmar que no puede haber burla y cortesía en el mismo enunciado y, por consiguiente, no encontraremos cortesía en la ironía con efecto negativo. Sin embargo, a continuación vamos a demostrar que hay enunciados irónicos con efecto positivo en los que la burla no está presente y puede aparecer en ellos cortesía. De esta manera, observaremos que se produce una conciliación entre cortesía e ironía.

\subsection{Ironía con efecto positivo}

La ironía con efecto positivo es aquella que se produce sin que la burla esté presente y puede haber o no presencia de cortesía. En este tipo de ironía hacemos una doble distinción, según se centre la ironía en el hablante o en la integración del mismo en un grupo. Si se da auto-ironía, la ironía está centrada en la autonomía del hablante y estamos ante una ironía con efecto positivo y de imagen negativa; mientras que si se da el segundo caso, esto es, si la ironía se centra en la integración del hablante en un grupo, estamos ante ironía con efecto positivo y de imagen positiva. Veamos el siguiente ejemplo en el que A está hablando con su abuelo $\mathrm{C}$ sobre los exámenes:

(6) A: síii pero eso- te- tuvo exámeneh tamién ¿no?

$\mathrm{C}: \mathrm{mmm} / \mathrm{sí}$

A: $(())$

C: (y eso)

A: $\vdots$ y lo aprobasteh todo?/jayy/ qué lista es!

C: sí/ listísima

A: (RISAS)

C: tuve suerte

(Briz y Grupo Val.Es.Co. 2002: 247 [BG.210.A.1])

En (6) C ironiza sobre ella misma, no para que su oyente se ría de ella, que es lo que ocurre si observamos la reacción de A, sino para que A reafirme lo que había dicho anteriormente (qué lista es). Como esto no ocurre, $\mathrm{C}$ debe intervenir de nuevo para intentar salvar su imagen social y mitigar el efecto que ha podido causar con su intervención. Según el Principio de Inversión, $\mathrm{C}$ da a entender con la utilización del superlativo que no es muy lista, sino poco lista. Como hemos visto anteriormente, se produce una inversión entre los términos muy/mucho y poco/nada; por lo que el grado de superlatividad del adjetivo equivale a la inversión del mismo. En este ejemplo, estamos ante una ironía con efecto positivo y de imagen negativa, ya que es el propio hablante el que ironiza sobre sí mismo pero siempre salvando su imagen de las posibles amenazas que puedan surgir en el intercambio conversacional. 
Además, podemos afirmar que la ironía con efecto negativo no se puede producir sobre uno mismo, ya que normalmente la auto-ironía lleva implícita una finalidad última que está lejos de querer causar daños sobre la imagen del propio individuo. En estos casos en los que el oyente habla sobre sí mismo, estaríamos ante una cortesía mitigadora, tal y como afirma Albelda (2003: 300) con la que se trata de reparar la imagen propia.

Por otra parte, la ironía con efecto positivo y de imagen positiva puede darse hacia su oyente, hacia una persona ausente o hacia una situación concreta, ya que en todos los casos se trata de utilizar la ironía como recurso para que el hablante se integre en un grupo. En este tipo de ironía, al igual que en el caso anterior, no aparece la burla, puesto que se trata de una ironía con efecto positivo. Veamos el ejemplo (7) en el que dos amigas hablan de la costumbre española de donar joyas a ciertas imágenes religiosas:

(7) [CB3,M,2,Me,EE,E]: Sí, [repetición] sí [/repetición], pues [/simultáneo] todos los años la [pausa] [/pausa] la Macarena, todo lo que luce de piedra[(s)] preciosas son de Juanita Reina. ¡Unos [pausa][/pausa] uno [(s)][repetición] pendientes to[(d)] [(o)]s!, ¡unos broches de esmeralda[ininteligible][/ininteligible][pausa][ipausa]! Todo lo deja Juanita Reina.

[CB8, M,2Bae,EE,V]: ¡Eh!, claro, de [palabra cortada] la[/palabra cortada] [pausa][/ pausa] las que tienen las joyas.

$[C B 1, M, 3, S u, E E, V]$ : Claro.

$[C B 8, M, 2 B a, E E, V]:$ Pues yo no [simultáneo] [ininteligible] [íninteligible] ninguna. [CB3, M,2,Me,EE,E]: Claro[simultáneo] [risas] [/risas]. Bueno le podemos dejar alguna pulserita de las que llevamos [risas] [/risas].

$[C B 8, M, 2 B a, E E, V]:$ Sí, también [fático=duda] [/fático] iban a hacer mucho con esta [pausa][jpausa] una pulserita de éstas.

(Corpus ALCORE, Campoamor)

En (7) V habla de una imagen religiosa, la Virgen de la Macarena, que lleva joyas donadas por una folklórica española, Juanita Reina. $V$ ironiza sobre el poco valor que tienen las pulseras que tanto $\mathrm{V}$ como $\mathrm{E}$ llevan consigo, ya que ellas no podrían donar joyas a la Virgen. Si explicamos este enunciado según el Principio de Inversión, observamos que E debe interpretar la afirmación de $\mathrm{V}$ de manera inversa, ya que podemos dejar alguna pulserita de las que llevamos quiere decir que no merece la pena que le dejen ninguna pulsera. E debe inferir con el uso del diminutivo que las pulseras que llevan no tienen valor alguno y precisamente este hecho es el que le sirve a V para ironizar sobre ello. Así, E interpreta la ironía y la continúa. Este caso es un ejemplo de ironía con efecto positivo y de imagen positiva hacia su oyente, ya que la finalidad última de la intervención irónica del hablante es que su oyente se integre en el grupo conversacional. Además, el oyente interpreta el enunciado irónico y continúa la ironía utilizando el diminutivo que antes había empleado $\mathrm{V}$ para mostrar que sus pulseras carecen de riqueza material. Hay presencia de cortesía, ya que estarían dispuestas a donarlas si no fuera porque tienen muy poco valor y su imagen social se vería dañada. Por tanto, esta presencia de cortesía es una estrategia que utiliza el hablante para producir ironía, ya que ambos saben que no pueden colaborar en la donación.

A continuación mostraremos un ejemplo referido a la ironía con efecto positivo y de imagen positiva hacia una persona ausente en la conversación. En este contexto aparecen dos hermanas hablando sobre el viaje de novios de una de ellas (V) y de los problemas que su marido tenía de comunicación: 
(8) V: ahí nos acabábamos de encontrar/ yo estaba ya un poco quicaut y luego encima hablar en inglés/ que hace cinco años que no hablo

A: y Roberto ¿qué? ¿se mosqueaba porque hablaras en inglés?

$\mathrm{V}$ : nooo ¡qué va! él dice que me entendía

A: ¿Roberto?

$\mathrm{V}$ : sí/ sí hombre no es que- no es un inglés muy académico el que hablo yo

(Briz y Grupo Val.Es.Co. 2002: 380 [IH.340.A.1])

En (8) se produce una ironía con efecto positivo y de imagen positiva hacia una persona ausente en la conversación, ya que $\mathrm{V}$ y $\mathrm{A}$ están hablando sobre el viaje de novios que ha realizado $\mathrm{V}$ a Nueva York y plantea los problemas que tenía de comunicación. Estamos ante una ironía con efecto positivo porque no hay presencia de burla sobre lo que se está diciendo, sólo ironía. Esta ironía se produce sobre el esposo de V, Roberto, que no está presente en la conversación y que por lo que se implica en el enunciado no habla inglés; de ahí que $\mathrm{A}$ se sorprenda cuando $\mathrm{V}$ afirma de forma irónica que su esposo le entendía cuando ella hablaba. Según el Principio de Inversión, en este enunciado debemos inferir que la información que dio Roberto no es del todo cierta, ya que tanto $\mathrm{A}$ como $\mathrm{V}$ saben que la persona de la que están hablando no habla inglés; por eso $\mathrm{V}$ enuncia esta ironía y A la reconoce e interpreta. Además, encontramos presencia de cortesía, ya que $\mathrm{V}$ justifica e intenta que no se dañe la imagen social de su esposo en el enunciado siguiente: no es un inglés muy académico el que hablo yo.

En (9) observamos ironía con efecto positivo y de imagen positiva referida a una situación. En este ejemplo, C está contando que le han gastado una broma telefónica, en la que le dicen que ha ganado dinero por contestar a una pregunta:

(9) C: me dice mire un muñeco que sale en la tele- no se me olvidará en la- en la VIDA/ que es rosa y tiene muchos pinchos ¿usted sabria decimos el nombre? digo pues Espinete- pues ha ganao usted cinco mil pesetas/// anote usted el nombre el-la-el teléfono// y llame que/ si en veinte segundos no llama pierde las cinco mil pesetas [yo digo=]
A: [normal]
C: ¡OST-A! pues si que he ganao yo cinco mil pesetas fácil
B: en un momento (RISAS)

(Briz y Grupo Val.Es.Co 2002: 235 [H.25.A.1])

En este ejemplo, B ironiza sobre la situación que cuenta $\mathrm{C}$ con la finalidad de integrarse en el grupo conversacional. Al igual que los casos anteriores, el oyente debe inferir que su hablante le está comunicando algo que no está diciendo y que debe interpretar según el Principio de Inversión, como una alteración de lo dicho, es decir, $\mathrm{B}$ con el enunciado en un momento no quiere decir realmente que $\mathrm{C}$ ganó dinero enseguida, sino que el oyente debe interpretar con ese enunciado que no se puede ganar dinero de manera fácil y rápida. Además, no se produce burla, ya que B intenta ser partícipe de la conversación; de ahí que estemos ante una ironía con efecto positivo y de imagen positiva hacia una situación concreta.

\section{Conclusiones}

En todos los ejemplos que hemos visto se han ejemplificado los distintos tipos de ironía que se han diferenciado según sus efectos y los contextos en los que se produce. De esta manera, podemos resumir los diferentes efectos en el siguiente esquema: 
- IRONÍA CON EFECTO NEGATIVO (Ausencia de cortesía, +/- burla)

-Hacia su oyente

-Hacia una persona ausente

-Hacia una situación

- IRONÍA CON EFECTO POSITIVO (Ausencia de burla, +/- cortesía)

$>$ Ironía de imagen negativa

-Auto-ironía

$>$ Ironía de imagen positiva

-Hacia su oyente

-Hacia una persona ausente

-Hacia una situación

Distinguimos ironía con efecto negativo y con efecto positivo dependiendo de si existe burla o no en la intención del hablante. Por una parte, la ironía con efecto negativo, es decir, la que conlleva burla, se puede producir hacia su oyente, hacia una persona ausente o hacia una situación concreta, como hemos visto en los ejemplos (3), (4) y (5). Por otra parte, la ironía con efecto positivo, en la que la burla no se encuentra presente, puede ser de dos tipos: de imagen negativa o de imagen positiva, según se refiera al mismo hablante o a la integración de éste en un grupo. La ironía con efecto positivo e imagen negativa (véase punto 4.2) está centrada en la auto-ironía que realiza el hablante como medio para salvaguardar su propia imagen del resto de miembros. Mientras que la ironía con efecto positivo e imagen positiva se centra en la integración del hablante en un grupo conversacional; para ello, la ironía puede producirse hacia su oyente, hacia una persona ausente en la conversación o hacia una situación. En todos estos casos en los que la ironía no conlleva burla, la cortesía puede estar presente, pero no de forma necesaria, sino opcional. Sin embargo, cuando un enunciado irónico sea además cortés, la ironía siempre tendrá efecto positivo, ya que la ironía con efecto negativo no permite la presencia de cortesía.

Por todo ello, afirmamos que la ironía es un proceso pragmático en el que el significado viene dado por el contexto en el que se produce y por la respuesta que causa en su oyente, según el análisis del Principio de Inversión que propone GRIALE. De ahí, la importancia que tiene el efecto que produce la ironía en la conversación, ya que varía la interpretación del oyente si está ante una ironía con efecto positivo o ante una ironía de efecto negativo. La cortesía en la conversación no puede estar presente cuando haya efecto negativo, puesto que se produciría una contradicción, ya que la burla y la cortesía no se pueden dar a la vez, y sólo aparece cuando estemos ante una ironía en la que el hablante no utilice la burla en su enunciado, esto es, en la ironía de efecto positivo.

Todo esto refutaría las creencias que llevan a relacionar la ironía con la descortesía, ya que siempre se ha entendido que la ironía era descortés, debido a que se ha identificado la ironía en general con un tipo de ironía en particular: la ironía de efecto negativo, que es la que conlleva burla. En este artículo, hemos intentado demostrar que hay ironía con efecto positivo que no conlleva burla y que, por tanto, puede resultar cortés. 


\section{Referencias bibliográficas}

Alba Juez, L. (1995): "Irony and politeness". En Revista Española de Lingüística Aplicada, 10, págs. $9-16$.

Alvarado, M.B. (en prensa): "Las marcas de la ironía". En Interlingüistica, 16.

Albelda, M. (2003): "Los actos de refuerzo de la imagen en la cortesía peninsular". En Bravo, D. (ed.), págs. 298-305.

Azorín Fernández, D. (Coord.) (2002): ALCORE. Alicante Corpus del Español. ISBN: 84-7908-684$\mathrm{X}$.

Bravo, D. (1997): “Imagen positiva vs. Imagen negativa?: pragmática socio-cultural y componentes de face". En Oralia, 2, págs. 155-184.

Bravo, D. (2003): "Actividades de cortesía, imagen social y contextos socioculturales: una introducción”. En Bravo, D. (ed.), págs. 98-108.

Bravo, D. (ed.)(2003): Actas del Primer coloquio del programa EDICE: La perspectiva no etnocentrista de la cortesia: identidad sociocultural de las comunidades hispanohablantes. Estocolmo, Universidad de Estocolmo.

Bravo, D. y A. Briz, (eds.)(2004): Pragmática sociocultural: estudios sobre el discurso de cortesia en español. Barcelona, Ariel.

Briz, A. y Grupo Val.Es.Co. (2002): Corpus de conversaciones coloquiales. Madrid, Arco Libros.

Brown, P. y S. Levinson (1978, 1987): Politeness: Some universals in language usage. New York, Cambridge University Press.

Díaz Pérez, F.J. (2003): La cortesía verbal en inglés y en español. Actos de habla y pragmática intercultural. Jaén, Universidad de Jaén.

Ducrot, O. (1986): "Esbozo de una teoría polifónica de la enunciación". En El decir y lo dicho. Polifonia de la enunciación. Barcelona, Paidós, págs. 175-238.

Escandell Vidal, M.V. (1995): "Cortesía, fórmulas convencionales y estrategias indirectas". En Revista Española de Lingüística, 25, 1, págs. 21-66.

Escandell Vidal, M.V. (1996): Introducción a la pragmática. Barcelona, Ariel.

Fernández García, F. (2001): "Ironía y (des)cortesía". En Oralia, 4, págs. 103-127.

Grice, H.P. (1975, 1991): "Lógica y conversación", en Valdés, L. (ed.): La búsqueda del significado. Murcia, Tecnos, págs. 511-530.

Haverkate, H. (1985): "La ironía verbal: análisis pragmalingüístico". En Revista Española de Lingüística, 15,2 , págs. $343-391$.

Haverkate, H. (1994): La cortesía verbal. Estudio pragmalingüistico. Madrid, Gredos.

Haverkate, H. (2003): "El análisis de la cortesía comunicativa: categorización pragmálingüística de la cultura española". En Bravo, D: (ed.), págs. 60-70.

Lakoff, R. (1973): "The logic of politeness or minding your p's and q's". En Papers from the Ninth Regional Meeting of the Chicago Linguistic Society. Chicago, Chicago Linguistic Society, págs. 292-305.

Leech, G.H. (1983): Principles of Pragmatics. Londres, Longman.

Levinson, S. (2000): Presumptive meanings. Cambridge, MIT Press.

Matsumoto, Y. (1988): "Reexamination of the universality of face: Politeness phenomenoa in japanese". En Journal of Pragmatics, 12, págs. 403-426.

Muecke, D.C. (1978): "Irony markers", Poetics, 7, págs. 363-375.

Padilla, X. (2005): "Del oyente receptor al oyente combatiente". En Estudios de Lingüística de la Universidad de Alicante, 18, págs. 213-230.

Reyes, G. (1984): Polifonia textual: la citación en el relato literario. Madrid, Gredos.

Reyes, G. (1992): "Lo serio, lo irónico y la búsqueda de interlocutor". En Voz y Letra, III/I, págs. $19-34$. 
Reyes, G. (2002): Metapragmática: Lenguaje sobre lenguaje, ficciones y figuras. Valladolid, Secretariado de publicaciones.

Ruiz Gurillo, L., Marimón, C., Padilla, X., y L. Timofeeva (2005): "El proyecto GRIALE para la ironía en español: conceptos previos". En Estudios de Lingüistica de la Universidad de Alicante, 18 , págs. 231-242.

Schoentjes, P. (2003): La poética de la ironía. Madrid, Cátedra.

Torres Sánchez, M.A. (1999): Aproximación pragmática a la ironía verbal. Cádiz, Servicio de publicaciones de la Universidad de Cádiz.

Wilson D. y D. Sperber (2004): "La teoria de la relevancia". En Revista de Investigación Lingüística, VII, págs. 233-282. 